\title{
Drs. Maharaj and Chandran reply
}

To the Editor:

We thank Dr. Rothschild ${ }^{1}$ for raising an important issue. We do agree with you that synostosis does occur in spondyloarthritis, as has been well documented. We were anticipating this question and hence included radiographs of the hands in the specific patient. There are no radiographic features of psoriatic arthritis (PsA) such as erosions, new bone formation, and pencil-in-cup appearance on any other radiographs of this patient. Moreover, radioulnar joint involvement is quite uncommon in patients with PsA. The typical radiographic features and the absolute symmetry of these lesions support a diagnosis of congenital fusion of the superior radioulnar joint ${ }^{2}$. Had this been synostosis related to the PsA, one would have expected, at least, some radiographic evidence elsewhere.

AJESH B. MAHARAJ, FCP(SA), Department of Clinical Immunology and Rheumatology, Academic Medical center, University of Amsterdam, Amsterdam, the Netherlands; VINOD CHANDRAN, PhD, Department of Medicine, Division of Rheumatology, University of Toronto, and Centre for Prognosis Studies in the Rheumatic Diseases, Toronto Western Hospital, Toronto, Ontario, Canada. Address correspondence to Dr A.B. Maharaj, Academic Medical Center, Immunology and Rheumatology, University of Amsterdam, Amsterdam, 1100 DD, the Netherlands.

E-mail: maharaja30@ukzn.ac.za

\section{REFERENCES}

1. Rothschild BM. Primary or secondary synostosis: the culmination of the spondyloarthritis form of erosive arthritis? J Rheumatol 2015;42:1062-3.

2. Simmons BP, Southmayd WW, Riseborough EJ. Congenital radioulnar synostosis. J Hand Surg Am 1983;8:829-38.

J Rheumatol 2015;42:6; doi:10.3899/jrheum.150254 